Proceeding Paper

\title{
Application of Marine Predator Algorithm in Solving the Problem of Directional Overcurrent Relay in Electrical Power System ${ }^{\dagger}$
}

\author{
Abdul Wadood ${ }^{1, *}$, Shahbaz Khan ${ }^{1}$, Bakht Muhammad Khan ${ }^{1}$, Husan Ali ${ }^{1}$ and Zabdur Rehman ${ }^{2}$ \\ 1 Department of Electrical Engineering, Air University Islamabad Kamra Campus, Kamra 43750, Pakistan; \\ shahbaz@au.edu.pk (S.K.); bakht@aack.au.edu.pk (B.M.K.); husan@aack.au.edu.pk (H.A.) \\ 2 Department of Mechanical Engineering, Air University Islamabad Kamra Campus, Kamra 43750, Pakistan; \\ zabd@aack.au.edu.pk \\ * Correspondence: wadood@au.edu.pk \\ + Presented at the 1st International Conference on Energy, Power and Environment, Gujrat, Pakistan, \\ 11-12 November 2021.
}

check for updates

Citation: Wadood, A.; Khan, S. Khan, B.M.; Ali, H.; Rehman, Z Application of Marine Predator Algorithm in Solving the Problem of Directional Overcurrent Relay in Electrical Power System. Eng. Proc. 2021, 12, 9. https://doi.org/ 10.3390/engproc2021012009

Academic Editor: Nazam Siddique

Published: 22 December 2021

Publisher's Note: MDPI stays neutral with regard to jurisdictional claims in published maps and institutional affiliations.

Copyright: (C) 2021 by the authors. Licensee MDPI, Basel, Switzerland. This article is an open access article distributed under the terms and conditions of the Creative Commons Attribution (CC BY) license (https:// creativecommons.org/licenses/by/ $4.0 /)$

\begin{abstract}
In electrical power systems, directional overcurrent relay (DOCR) coordination is assumed to be an essential component of the system for protection purposes. To diminish and reduce power losses, the coordination between these relays ought to be kept at an ideal value to minimalize the overall operating time of all primary-relay shortcoming situations. The coordination of DOCR is a complex and profoundly compelling nonlinear problem. The objective function is to minimalize the overall total operating time of all essential relays to minimize inordinate breakdown and interference. Coordination is performed using the marine predator algorithm (MPA), inspired by a widespread foraging strategy, namely Lévy and Brownian movements, to search for global optimal solutions in order to resolve the DOCRs coordination issue. The results acquired from MPA are equated with other state-of-the-art algorithms, and it was observed that the proposed algorithm outperforms other algorithms.
\end{abstract}

Keywords: marine predator optimization (MPA); time dial setting (TDS); plug setting (PS); DOCRs

\section{Introduction}

With the increasing demand for power on the consumer's side, the incorporation of distributed generation (DG) units has been on rise [1]. With this trend, protection coordination problems need to be considered for smooth and uninterrupted operation of distribution networks [2]. Due to presence of DGs in distribution networks, complexity is increased because of the bidirectional flow of current and the varying fault currents [3]. Because of these mentioned scenarios, conventional protection schemes are unable to fulfill protection tasks, as these methods are based on predetermined fault currents. Directional overcurrent relays (DOCRs) have been increasingly used in distribution networks due to their ease of installation and better performance. DOCRs have been used in electrical networks as main and backup protection systems [4]. Therefore, coordination of DOCR by using different optimization algorithms is a current topic [5]. The settings of DOCR rely on three design variables for optimization; time multiplier settings (TMS), plug settings (PS), and pickup current (Ip). The DOCR problem in a multi loop transmission system has been resolved in [6]. As modern electrical networks have increased in terms of complexity, the chances of trapping local optima are high for these conventional approaches. Conversely, metaheuristic algorithms have better chance of avoiding local optimum values, as they start from random initial solutions and have randomness and diversity [7]. Various metaheuristic algorithms have been used to address and resolve the DOCR issue. Metaheuristic algorithms, such as the water cycle [8], improved firefly [9], BBO [10], Harris hawk optimization [11], continuous particle swarm optimizer [12], whale optimization [13], 
new-rooted tree algorithm [14], GA [15], and HS [16], have been used. This paper presents a marine predator algorithm (MPA) for the DOCR optimization problem. MPA is a recent algorithm [17]. This algorithm is based on the foraging and capturing strategies employed by marine predators. It uses Brownian motion as well as the Lévy flight mechanism to capture prey. These strategies make this algorithm suitable for application in DOCR optimization.

\section{Problem Formulation and Coordination Constraints}

The DOCRs issue can be regarded as non-linear non-convex problem. The key aim is to minimalize the overall operational time of the relaying system. Equation (1) shows the objective function and constraints for the relay optimization problem:

$$
\begin{gathered}
T_{i}=\frac{\propto \times T M S}{\left[\left(\frac{I_{f i}}{I_{p i}}\right)^{\beta}-1\right]} \\
T D S_{\text {min }} \leq T D S \leq T D S_{\text {max }} \\
P S_{\text {min }} \leq P S \leq P S_{\text {max }} \\
T_{b}-T_{p} \geq C T I
\end{gathered}
$$

where $\alpha$ and $\beta$ are variables, with values of 0.14 and 0.02 respectively. TDS and PS are the time dial settings and plug settings, and CTI stands for the time-interval coordination.

\section{Marine Predictor Algorithm}

An outline of the MPA is introduced in the following phase: initially the prey can originate from exploration or the search spaced method, and fitness can be determined by the survival of the fittest theory

$$
\begin{aligned}
X_{o} & =X_{\text {min }}+\operatorname{rand}\left(X_{\text {max }}-X_{\text {min }}\right) \\
\text { Elite }= & {\left[\begin{array}{cccc}
x_{1,1}^{I} & x_{1,2}^{I} & \cdots & x_{1, d}^{I} \\
x_{2,1}^{I} & x_{2,2}^{I} & \cdots & x_{2, d}^{I} \\
\vdots & \vdots & \vdots & \vdots \\
\vdots & \vdots & \vdots & \vdots \\
x_{n, 1}^{I} & x_{n, 2}^{I} & \cdots & x_{1, d}^{I}
\end{array}\right]_{n \times d} }
\end{aligned}
$$

where $X_{\min }$ and $X_{\max }$ are the lower and upper bounds. $x_{1,1}^{I}$ introduces the top MP vector.

\subsection{MPA Optimization Process}

MPA optimization is further distributed into three stages, i.e., the unit velocity, high velocity, and low velocity ratios.

\section{Stage 1: High Velocity Ratio}

In this phase, prey begins to find the exploration or search space by utilizing the Brownian technique for tracking down promising locales that might it might incorporate into an ideal arrangement.

$$
\begin{gathered}
\text { while iter }<\frac{1}{3} \text { Max_Iter } \\
\overrightarrow{\text { stepsize }_{i}}=\overrightarrow{R_{B}} \otimes\left(\overrightarrow{\text { Elite }_{i}}-\overrightarrow{R_{B}} \otimes \overrightarrow{\text { Prey }_{i}}\right) i=1, \ldots, n \\
{\overrightarrow{\text { Prey }_{i}}}={\overrightarrow{\text { Prey }_{i}}}_{P}+P \cdot \vec{R} \otimes \overrightarrow{\text { stepsize }}_{i}
\end{gathered}
$$


Stage 2: Unit Velocity Ratio

This phase utilizes both exploration and exploitation, and these are designed according to the populace; half of the population is assigned for investigation and the remainder is for exploitation.

$$
\begin{aligned}
& \text { while iter }<\frac{1}{3} \text { Max }_{\text {Iter }}<\frac{2}{3} \text { Max Iter }_{\text {Ite }} \\
& \text { For the first half of the population } \\
\overrightarrow{\text { stepsize }_{i}}= & \overrightarrow{R_{L}} \otimes\left(\overrightarrow{\text { Elite }_{i}}-\overrightarrow{R_{L}} \otimes \overrightarrow{\text { Prey }_{i}}\right) i=1, \ldots, n / 2 \\
& \overrightarrow{\text { Prey }_{i}}=\overrightarrow{\text { Prey }_{i}}+P \cdot \vec{R} \otimes \overrightarrow{\text { stepsize }_{i}} \\
\overrightarrow{\text { stepsize }_{i}}= & \overrightarrow{R_{B}} \otimes\left(\overrightarrow{R_{B}} \otimes \overrightarrow{\text { Elite }_{i}}-\overrightarrow{\text { Prey }_{i}}\right) i=n / 2, \ldots, n \\
& \overrightarrow{\text { Prey }_{i}}=\overrightarrow{\text { Elite }_{i}}+P \cdot C F \otimes \overrightarrow{\text { stepsize }_{i}}
\end{aligned}
$$

Stage 3:

This phase adopts the low-velocity ratio, i.e., predator Lévy $(v=0.1)$ at the point when the predator is moving quicker than the prey with a low-speed proportion.

$$
\begin{aligned}
& \text { while iter }<\frac{2}{3} \text { Max }_{\text {Iter }} \\
& \overrightarrow{\text { stepsize }_{i}}=\overrightarrow{R_{L}} \otimes\left(\overrightarrow{R_{L}} \otimes{\overrightarrow{\text { Elite }_{i}}}_{-} \overrightarrow{\text { Prey }_{i}}\right) i=1, \ldots, n \\
& \overrightarrow{\text { Prey }_{i}}=\overrightarrow{\text { Elite }_{i}}+P \cdot C F \otimes \overrightarrow{\text { stepsize }}_{i}
\end{aligned}
$$

\subsection{FADs Effect and Eddy Formation and MPA Memory}

MPA spend over $80 \%$ of the time in the prompt area of FADs, and for the remaining $20 \%$ yields extended leaps in various measurements, which are likely to discover a climate with another dispersion of prey. Marine predator simulates using memory savings in MPA. When it executes the prey and FADs impacts, separately, this framework should be assessed for its wellness to determine the elite value.

$$
\overrightarrow{\text { Prey }_{i}}= \begin{cases}\overrightarrow{\text { Prey }}_{i}+C F\left[\overrightarrow{X_{\text {min }}}+\vec{R} \otimes\left(\overrightarrow{X_{\max }}-\overrightarrow{X_{\min }}\right] \otimes \vec{U}\right. & \text { if } r \leq F A D s \\ \overrightarrow{\text { Prey }_{i}}+[\text { FADs }(1-r)+r]\left(\overrightarrow{\text { Prey }_{r 1}}-\overrightarrow{\text { Prey }_{r 1}}\right) \vec{U} & \text { if } r>\text { FADs }\end{cases}
$$

\section{Results and Discussion}

MPA is tested on an IEEE-9 bus system, as depicted in Figure 1. The different combination and short system test is mentioned in [14]. The ration for the CT was set to be 500/1 for all DOCRs. The higher and lower ranges of TDS and PS were set to be 1.2 to 0.1 and 2.5 to 0.5 , with a CTI of $0.2 \mathrm{~s}$. The best and finest solution achieved is given in Table 1 , which shows that MPA provided an optimal solution to the DOCR problem. The MPA has the benefit of an overall net improvement in the total operating time of $5.44 \mathrm{~s}, 1.308 \mathrm{~s}$, 10.87 s, 24.07 s, and 20.3 s, over the PSO, HS, NLP, GA, and BBO techniques mentioned in References [7,10,14,15]. 


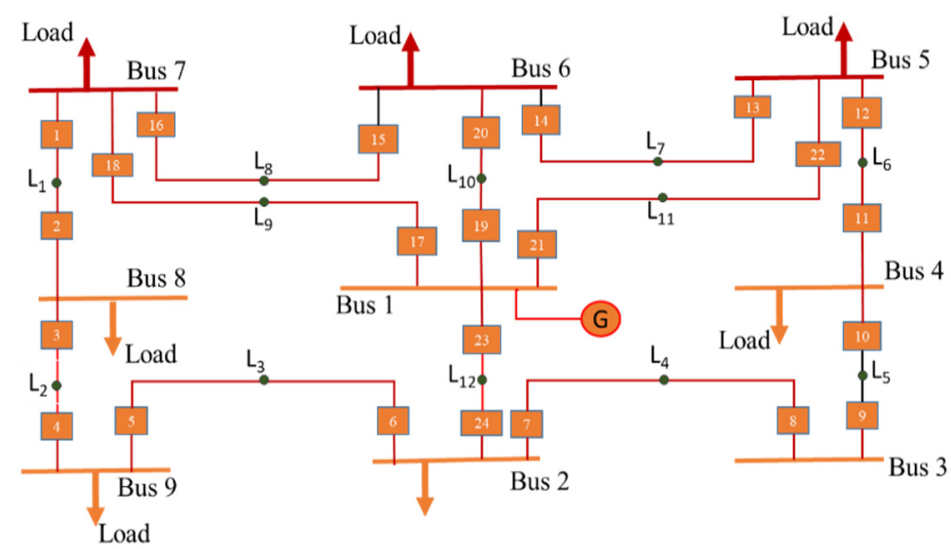

Figure 1. IEEE 9 bus.

Table 1. Optimum value of TDS and PS for NINE bus system.

\begin{tabular}{cccccc}
\hline Relay & TDS & PS & Relay & TDS & PS \\
\hline 1 & 0.1014 & 0.5012 & 13 & 0.1000 & 1.7300 \\
2 & 0.1003 & 0.5990 & 14 & 0.1000 & 1.4400 \\
3 & 0.1000 & 0.7150 & 15 & 0.1000 & 1.5650 \\
4 & 0.1000 & 0.5146 & 16 & 0.1021 & 0.6939 \\
5 & 0.1050 & 0.6057 & 17 & 0.1005 & 0.6500 \\
6 & 0.1011 & 0.8010 & 18 & 0.1010 & 0.6741 \\
7 & 0.1000 & 0.9050 & 19 & 0.1013 & 0.8010 \\
8 & 0.1000 & 0.9011 & 20 & 0.1000 & 0.9016 \\
9 & 0.1031 & 0.6870 & 21 & 0.1000 & 1.200 \\
10 & 0.1012 & 0.7132 & 22 & 0.1021 & 0.5791 \\
11 & 0.1030 & 0.9220 & 23 & 0.1011 & 0.8715 \\
12 & 0.1015 & 0.6656 & 24 & 0.1000 & 0.9441 \\
\hline
\end{tabular}

\section{Conclusions}

In this paper, the MPA optimization technique procedure is used to tackle the DOCR coordination issue, which is expressed as a MINLP, focusing on minimizing the total operating time of all main relays by choosing the decision variables for TDS and PS. The distinctive prevalent searching procedures, namely Lévy and Brownian movements in ocean predators, alongside an ideal experience rate strategy among a hunter and prey, has been found to be useful in searching for the optimal global solution. A comparison of MPA with other optimization techniques provides an improved and optimal solution and is an important tool for the DOCR coordination problem.

Data Availability Statement: The data used to support the finding of this study are included within the article.

\section{References}

1. Gamarra, C.; Guerrero, J. Computational optimization techniques applied to microgrids planning: A review. Renew. Sustain. Energy Rev. 2015, 48, 413-424. [CrossRef]

2. Giraldo, J.S.; Castrillon, J.A.; Lopez, J.C.; Rider, M.J.; Castro, C.A. Microgrids Energy Management Using Robust Convex Programming. IEEE Trans. Smart Grid 2018, 10, 4520-4530. [CrossRef]

3. Lasseter, R.; Paigi, P. Microgrid: A conceptual solution. In Proceedings of the 2004 IEEE 35th Annual Power Electronics Specialists Conference (IEEE Cat. No. 04CH37551), Aachen, Germany, 20-25 June 2004; Volume 6.

4. Wadood, A.; Khurshaid, T.; Farkoush, S.G.; Yu, J.; Kim, C.H.; Rhee, S.B. Nature-inspired whale optimization algorithm for optimal coordination of directional overcurrent relays in power systems. Energies 2019, 12, 2297. [CrossRef]

5. Serna, J.; de Jesús, J.; López-Lezama, J.M. Alternative methodol-ogy to calculate the directional characteristic settings of directional overcurrent re-lays in transmission and distribution networks. Energies 2019, 12, 3779. [CrossRef] 
6. Wadood, A.; Farkoush, S.G.; Khurshaid, T.; Kim, C.-H.; Yu, J.; Geem, Z.W.; Rhee, S.-B. An Optimized Protection Coordination Scheme for the Optimal Coordination of Overcurrent Relays Using a Nature-Inspired Root Tree Algorithm. Appl. Sci. 2018, 8, 1664. [CrossRef]

7. Alam, M.N.; Das, B.; Pant, V. A comparative study of metaheuristic optimization approaches for directional overcurrent relays coordination. Electr. Power Syst. Res. 2015, 128, 39-52. [CrossRef]

8. Haider, Z.M.; Mehmood, K.K.; Khan, S.U.; Khan, M.O.; Wadood, A.; Rhee, S.-B. Optimal Management of a Distribution Feeder During Contingency and Overload Conditions by Harnessing the Flexibility of Smart Loads. IEEE Access 2021, 9, 40124-40139. [CrossRef]

9. Khurshaid, T.; Wadood, A.; Farkoush, S.G.; Kim, C.-H.; Yu, J.; Rhee, S.-B. Improved Firefly Algorithm for the Optimal Coordination of Directional Overcurrent Relays. IEEE Access 2019, 7, 78503-78514. [CrossRef]

10. Albasri, F.A.; Alroomi, A.R.; Talaq, J.H. Optimal Coordination of Directional Overcurrent Relays Using Biogeography-Based Optimization Algorithms. IEEE Trans. Power Deliv. 2015, 30, 1810-1820. [CrossRef]

11. Irfan, M.; Wadood, A.; Khurshaid, T.; Khan, B.M.; Kim, K.-C.; Oh, S.-R.; Rhee, S.-B. An Optimized Adaptive Protection Scheme for Numerical and Directional Overcurrent Relay Coordination Using Harris Hawk Optimization. Energies 2021, 14, 5603. [CrossRef]

12. Wadood, A.; Kim, C.-H.; Khurshiad, T.; Farkoush, S.G.; Rhee, S.-B. Application of a Continuous Particle Swarm Optimization (CPSO) for the Optimal Coordination of Overcurrent Relays Considering a Penalty Method. Energies 2018, 11, 869. [CrossRef]

13. Khurshaid, T.; Wadood, A.; Farkoush, S.G.; Yu, J.; Kim, C.-H.; Rhee, S.-B. An Improved Optimal Solution for the Directional Overcurrent Relays Coordination Using Hybridized Whale Optimization Algorithm in Complex Power Systems. IEEE Access 2019, 7, 90418-90435. [CrossRef]

14. Wadood, A.; Khurshaid, T.; Farkoush, S.G.; Kim, C.H.; Rhee, S.B. A bio-inspired rooted tree algorithm for optimal coordination of overcurrent relays. In Proceedings of the International Conference on Intelligent Technologies and Applications, Bahawalpur, Pakistan, 23-25 October 2018; Springer: Berlin/Heidelberg, Germany, 2018; pp. 188-201.

15. Bedekar, P.P.; Bhide, S.R. Optimum Coordination of Directional Overcurrent Relays Using the Hybrid GA-NLP Approach. IEEE Trans. Power Deliv. 2010, 26, 109-119. [CrossRef]

16. Bouchekara, H.; Zellagui, M.; Abido, M. Optimal coordination of directional overcurrent relays using a modified electromagnetic field optimization algorithm. Appl. Soft Comput. 2017, 54, 267-283. [CrossRef]

17. Faramarzi, A.; Heidarinejad, M.; Mirjalili, S.; Gandomi, A.H. Marine Predators Algorithm: A nature-inspired metaheuristic. Expert Syst. Appl. 2020, 152, 113377. [CrossRef] 